strong Scandinavian words (the meaning of which I can only imagine), I could see the muscles struggling against the weight to bring up the hand again. After a few minutes, the muscles, which are thus undergoing a course of fresh education, give way through sheer exhaustion, and the patient, by a seemingly fearful effort of the will, has gained a step on the road to recovery. Then the Doctor works over the course of the nerves with the nail of his thumb or finger, and seems to find them out with unerring precision; the result of this manipulation being the feeling, as it were, of an electrical shock through the different series of museles to which the nerve is distributed. It is worthy of remark that, since this patient has been under Dr. Kellgreen's manipulative and educational treatment, about twenty-four shot-corns have worked their way up to the skin out of the deeper tissues. From September, 1875, to March, 1876, surgeons had sought constantly for them, but. without success. Exercise has evidently brought them out Whether galvanism could have brought about such a result or not I cannot say; but of this $I$ am sure, that no other method of treatment than that which has been adopted could have been attended with better results.

I saw other cases during my visit which are of great interest as regards treatment and result, but it is impossible to speak of them here. I came to the conclusion that Dr. Kellgreen's method of treatment must be in certain cases of extreme value; and I feel sure that many a busy practitioner would be glad to know where such honest and skilful manipulative treatment may be obtained, and where nerves and muscles which have from any cause been thrown out of working order may obtain a course of education which may restore them once more to their sphere of usefulness.

Cleveland.square, $w$.

\section{ON THE EXPECTANT TREATMENT OF CHOREA.}

Bx E. B. GRAY, M.D.; AND H. M. TUCKWELL, M.D., PHYSICIANS TO THE RADCLIFFR INFIRMABY, OXFORD.

Nearly five years have elapsed since we published in this journal* a series of cases of chorea, in the treatment of which all medicines had been withheld, and reliance had been placed solely on nursing and good diet. We then showed by a comparison of the average duration of our cases with the average duration of cases treated with arsenic and other routine drugs, that the expectant treatment was at least as successful as the treatment by medicine. Since that time we have continued to work in the same direction, and are now able to record twenty more cases, in which the whole natural duration of the disease uninfluenced by medicine has been accurately estimated. In every instance the parents or friends were closely questioned as to the earliest appearance of twitching, and the patient was kept under observation till all irregular movements had ceased. We propose to give, as before, only a brief résuné of the clinical history of each case; and, in order to avoid repetition, we would state at the outset that the best diet of the hospital was given to all alike, and, in place of medicine, an occasional dose of sugared water or carraway water, as a placebo.

\section{(Under the care of Dr. Gray.)}

1. Girl, aged fifteen. Firsc attack, bilateral, mild. For the first ten days after admission high temperature $\left(100^{\circ}-102^{\circ}\right)$; basic systolic murmur, which ceased to be heard as the chorea got well. Duration before admission, four weeks; movements ceased five weeks after admission: total duration, nine weeks.

2. Boy, aged fourteen. First attack, bilateral, mild, supervening upon a fortnight's attack of subacute rheumatism in knees, ankles, and loins. Father said to have had rheumatic fever, and one sister said to be epileptic. No cardiac murmur. Duration before admission, three weeke; movements ceased eight weeks after admission : total duration, eleven weeks.

3. Girl, aged nine. First attack, bilateral, mild. Mother had had rheunatic fever, and an aunt had been choreic at the same age. No cardiac murmur. Duration before admission, three weeks; movements ceased six weeks after admission. The child was still, however, kept under observation. For the next fortnight she had, together with a systolic murmur at the apex (constant in the recumbent, but disappearing in the erect position), an attack of erythema papulatum, very symmetricul, first on the legs, then on the arms; also a whitlow on one thumb. At the end of three weeks, the erythema having subsided, chorea returned sharply, with a rise in the temperature, excited action of the heart, and a systolic murmur at apex and base, audible in the recumbent, doubtfully audible in the erect posture. At the end of anotber nine days this second attack of chorea had quite subsided, the murmur remaining much as before, and still dependent on posture. Total duration, including the relapse, thirteen weeks.

4. Boy, aged sixteen. First attack, moderately severe, affecting chiefly the facial and respiratory muscles, and the right limbs more than the left. No history of rheumatism. On admission, a slight basic, systolic, cardiac murmur was heard, which ceased to be audible after a few days. Duration before admission four weeks; movements ceased six weeks after admission: total duration, ten weeks.

5. Girl, aged twalve. First attack, bilateral, mild. A brotber bad been choreic. Mitral systolic murmur for several days after admission. Duration before admission, three weeks; movements ceased six weeks after admission total duration, nine weeks.

6. Boy, aged nine. First attack, bilateral, mild. No history of rheumatism, no cardiac murmur. Duration before admission, two weeks; movements ceased four weeks after admission: total duration, six weeks.

7. Boy, aged seven. First attack, left bemichorea, mild. No history of rheumatism. For several days the heart's action was excited, and the impulse increased, but no murmur was beard. Duration before admission, two weeks; movements ceased three weeks after admission : total duration, five weeks.

8. Woman, aged twenty-six; married four years; never pregnant, and still menstruating regularly. First attack, general, moderately severe. No history of rheumatism, but the chorea was attributed to fright. On admission a systolic murmur was heard at the apex, but was scarcely audible when she was discharged cured. No albumen in the urine. Duration before admission, five months; movements ceased one month after admission: total duration, twenty-four weeks.

9. Boy, aged eleven. First attack, bilateral, rather severe; supervening on an attack of acute rheumatism. Mitral systolic murmur heard throughout. Duration before admission, three weeks; movements ceased ten weeks after admission : total duration, thirteen weeks.

\section{(Under the care of Dr. TuckweLL.)}

10. Giri, aged twelve. First attack; left hemichorea, moderately severe. She had had at times pains in the joints, and her mother had had rheumatic fever. No cardiac murmur. Duration before admission, four days; movements ceased in from seven to eight weeks after admission : total duration, eight weeks.

11. Girl, aged four. First attack, general, moderately severe. No history of rheumatism in the cbild or her parents, but her aunt had had chorea when young. Loud systolic mitral murmur, heard plainly beneath the scapula, becoming less loud as the chorea abated, but not disappearing after recovery. Duration before admission, ten days; movements ceased twenty-five days after admission: total duration, five weeks.

12. Girl, aged eleven. Third atfack, general, mild. She had suffered repeatedly from severe pain in the joints. No cardiac murmur. Duration before admission, four weeks; movements ceased five weeks after admission: total duration, nine weeks.

13. Girl, aged nine. First attack, general, moderately severe; began with pains in the wrists and ankles. Loud mitral systolic murmur heard beneath the scapula, distinctly lessening in intensity as the chorea abated, but not disappearing after recovery. Duration before admission, 
three weeks; movements ceased seven weeks after admission : total duration, ten weeks.

14. Girl, aged fifteen. Second attack; left hemichorea, mild. No history of rheumatism. Short systolic murmur at apex, not heard beneath the scapula, becoming less distinct as the chorea abated, and finally disappearing. Duration before admission, one week; movements ceased seven weeks after admission : total duration, eight weeks.

15. Boy, aged thirteen. First attack; right hemichorea, moderately severe. Had painful swelling of the right anlsle shortly before the chorea began. Mother rheumatic. Short systolic murmur at apex and base, both of which ceased to be heard as the chorea got well. Duration before admission, four weeks; movements ceased nine weeks after admission : total duration, thirteen weeks.

16. Girl, aged nine. Second attack, general, mild. No history of rheumatism. No cardiac murmur. Duration before admission, four weeks; movements ceased eight weeks after admission: total duration, twelve weeks.

17. Boy, aged thirteen. First attack, general, mild. Has had rheumatic swelling of the knees and ankles. An aunt had chorea when young. Blowing systolic murmur at the apex, not heard beneath the scapula; not changing its character as the chorea subsided. Duration before admission, two weeks; movements ceased three weeks after admission : total duration, five weeks.

18. Girl, aged fourteen. Second attack; right hemichorea, mild. No history of rheumatism. Systolic murmur at apex, disappearing gradually with the chorea. Duration before admission, ten days; movements ceased in from four to five weeks after admission: total duration, six weeks.

19. Girl, aged eleven. First attack, general, moderately severe. Had suffered from rheumatic pains in the joints for some weeks before admission. Her aunt and first cousin bad suffered from chorea when young. Systolic murmur at apex, disappearing gradually with the chorea. Duration before admission, four weeks ; movements ceased four weeks after admission : total duration, eight weeks.

The above are all instances of mild, or moderately severe, chorea. 'The following, which was under Dr. Tuckwell' care, is especially interesting, as showing the natural course of chorea in its very severe and violent form. Full notes of the case are therefore given.

20. A girl, aged nine, was admitted into the Radcliffe Infirmary on January 6th, 1872, suffering from a severe attack of general chorea. She was reported to have been ill only three days, the present attack being the first she had had. She had suffered, however, for some time hefore this illness from pains in the knees and ankles, though she had never had a regular attack of rheumatic fever. Her father was lying at the same time in the infirmary with a severe attack of rheumatic fever. Pulse 92 ; temperature the same evening, $99^{\circ}$; no cardiac murmur. She was ordered good diet, including minced meat and regetables, and a little carraway-water three times a day.

Jan. 7th. - She had passed a very bad night, much convulsed, and screaming so as to disturb the otber patients. The whole body was constantly and severely convulsed. The skin of the forehead, face, and ears was becoming eczematous, and the tip of the nose was getting fissured from friction against the pillow. Evening temperature $98 \cdot 6^{\circ}$. The first sound of the heart at the apex was immediately preceded by a short presystolic murmur. She was placed in a ward by herself, in a large crib well padded all round with pillows. She was ordered to be fed every two hours with milk, bread-and-milk, eggs beaten up in milk, light pudding; and to have once in the day a plate of ninced meat or fish and mashed potato. To continue the carrawayvater.

8th.-She had passed a very bad night, delirious and very convulsed. All the salient parts of the body were becoming sore from friction. She complained much of headache, but had no pain in the joints. Pulse 88 ; evening temperature $98.4^{\circ}$. She had taken nourishment regularly, and her bowels had acted naturally.

9th.- She had dozed two or three times during the night for about half an hour at a time, but had then started up more violent and convulsed than before. The face, as well as the nose, was getting fissured. Pulse 70 ; evening temperature $98^{\circ}$

10th. - She had passed another very bad night, screaming wildly, and terribly convulsed, so as to have once turned a complete somersault over the wall of pillows and the side of the crib on to the floor. When asked if she was in pain she put her hand to her head. Evening temperature $98.4^{\circ}$. The same short presystolic murmur was heard. She had continued to take food well.

11th.- She had had a natural sleep from 10 P.Mr. last night to 3 A.M. this morning. She had then started up again in a violent state of excitement, screaming, talking incoherently, and much convulsed. The choreic movements were, however, decidedly less severe. The lower lip, the cheeks, and nose were badly fissured. The backs of the wrists, the knuckles, the elbows, and the sides of the body were very sore and red, as if badly chapped. The body was very emaciated. Evening temperature $99 \cdot 6^{\circ}$. No cardiac murmur could, on careful auscultation, be heard.

12 th. - A remarkable improvement had taken place. She had slept during a great part of the previous day and at intervals during the night, and she was sleeping quietly at the time of the visit. No cardiac murmur could be beard. Erening temperature $98^{\circ}$. To continue the nourlshment. 13th. - Still further improvement had taken place, and she had passed a quiet night. The chorea bad abated in a remarkable manner, and, instead of being general, was limited to the face and neck, left arm and leg. Pulse 80 ; evening tein perature $98^{\circ}$. The skin on the affected parts was beginning to heal.

From this time forth she made a steady recovery, and was discharged cured on Feb. 19th, the total duration of the attack having been forty-seven days.

Remarks. - In our former communication we showed that the average duration of chorea treated on the expectant plan was, as far as our observations had then gone, from ten to eleven weeks; and that tho average duration of chorea treated with arsenic in gradually increasing doses, according to Begbie's plan, was likewise from ten to eleven weeks, the difference, if any, being slightly in favour of the expectant plan. We also compared these results with the estimate of Dr. Hillier, who, in his work on Diseases of Children, gives the mean duration of thirty cases treated with arsenic, \&c., as "about ten weeks"; and with Sée's estimate of "sixty-nine days," as the average duration of 117 cases treated with various medicines.

Of the twenty cases above recorded, the average duration is found to be rather over nine weeks, a still more favourable result than that before given. Or, taking the average of the whole thirty.eight cases published in this and the previous paper, we find nine weeks and six days to be the average duration of chorea treated without medicine. It is singular that this corresponds with Sée's average to a day.

Case 20 is worthy of special notice, in that it presented to view many of the worst features of chorea in its fatal form. The convulsions, so violent as to jerk the child over a high wall of pillows, like a fish, on to the floor, the body sore and fissured from friction, the rapid wasting, the wild delirium-were just the symptoms present in other cases which we have seen die in this infirmary, when plied with all sorts of active medicines. A very noteworthy point is the rapid improvement which took place naturally on the ninth and tenth days of the attack. Had a believer in arsenic been called in on the evening of the ninth day, and ordered large doses of Fowler's solution, the return of sleep and subsidence of the convulsions would, doubtless, have been attributed to the arsenic or to any other drugbromide of potassium, succus conii, Calabar bean, zine, iron, chloral, chloroform, \&c-which might have been ordered at that lucky, or unlucky, moment. This natural and restorative sleep might well be compared to the sleep which ushers in recovery in delirium tremens, and comes best of itself when a patient is well nursed and nourished, and kept free from all kinds of narcotics. An isolated ward; a good nurse; a large crib, well padded round, and walled in with pillows; plenty of nutritious food, without stimulants, - on these we shall feel inclined to rely in the treatment of severe chorea, till we obtain more conclusive evidence than has yet been adduced that the disease can, in the slightest degree, be favourably influenced by any medicine as yet discovered.

STEPs are being taken with a view to the establishment of a Seamen's Hospital at Antwerp somewhat similar to the Dreadnought Hospital at Greenwich. 